\title{
THE EFFECT OF VALVOTOMY ON THE MURMURS OF PULMONARY AND AORTIC STENOSIS
}

\author{
BY \\ BERTRAND G. WELLS \\ From St. Bartholomew's Hospital \\ Received December 27, 1957
}

It is not generally accepted that the character of the systolic murmur of pulmonary or aortic stenosis gives an indication of the severity of the stenosis. This is probably because the intensity of the murmur has attracted more interest than the timing and character of the vibrations. Greene et al. (1949) state that a systolic thrill was present in half their cases of idiopathic dilatation of the pulmonary artery. Despite this finding there have been a number of authorities who have claimed that the loudness of the systolic murmur is proportional to the severity of the stenosis (Currens et al., 1945; Dow et al., 1950; Donzelot et al., 1954; Mannheimer and Jonsson, 1954). Downing (1956) and Bailey et al. (1956) have found the murmur of aortic stenosis softer after aortic valvotomy.

The more widespread use of phonocardiography has enabled the duration of the systolic murmurs to be measured. Vogelpoel and Shrire (1955) have suggested that in cases of tetralogy of Fallot the duration of the murmur is inversely proportional to the severity of the stenosis. Mannheimer and Jonsson (1954) found that the peak intensity of the murmur of severe valvular pulmonary stenosis was later than that of moderate stenosis, but they did not comment on the duration of the murmurs.

There has been little interest in the frequency of the vibrations constituting the systolic murmurs of valvular and infundibular stenosis. The statements by Downing (1956) and Bailey et al. (1956) that the murmur of aortic stenosis is softer after valvotomy could be interpreted as an indication that the frequency is lower, but the term "softer" has probably been used to describe intensity rather than pitch. Mannheimer and Jonsson (1954) state that the murmur of pulmonary stenosis is of higher frequency than an innocent systolic murmur, but they have not related the frequency to the severity of the stenosis.

The relationship of the systolic murmur to the pulmonary and aortic components of the second heart sound has been the subject of considerable attention. Ordway et al. (1950) point out that in extreme pulmonary stenosis the pressure in the pulmonary artery may be lower than that in the right ventricle in both diastole and systole. It is therefore surprising that a continuous murmur is not audible in such cases. Reinhold and Nadas (1954) found that the murmur did extend into diastole in the most severe cases of pulmonary stenosis. Kjellberg et al. (1955) considered that stenosis of the infundibulum causes a longer silent interval between the end of the murmur and the pulmonary component of the second heart sound than is found in pulmonary valvular stenosis.

The present study was made to determine what changes are present in the systolic murmur after an operation to relieve valvular or infundibular stenosis. The changes were found to be definite. They showed that the severity of valvular stenosis could be assessed by studying the frequency of the vibrations and their timing in systole. The systolic murmur of infundibular stenosis changed after infundibular resection in a different manner from that of valvular stenosis after valvotomy. This throws light on the mechanism of prodution of these murmurs. 


\section{MATERIAL AND METHODS}

Twenty patients undergoing surgical treatment of valvular or infundibular stenosis by $\mathrm{Mr}$. O. S. Tubbs and Mr. I. M. Hill were studied. Three patients had an aortic valvotomy, combined in two cases with mitral valvotomy. Six patients had a pulmonary valvotomy for valvular pulmonary stenosis with a normal aortic root. Five patients had a pulmonary valvotomy for tetralogy of Fallot with valvular stenosis. Five patients had an infundibular resection for tetralogy of Fallot with infundibular stenosis. One patient had both a valvotomy and an infundibular resection for tetralogy of Fallot with valvular and infundibular stenosis. The age and sex of each patient are shown in Table I.

TABLE I

ANAlysis of Murmurs of Valvular aNd Infundibular Stenosis before AND after Operation in 20 PATIENTS

\begin{tabular}{|c|c|c|c|c|c|c|c|c|c|c|c|c|c|c|c|c|c|}
\hline \multirow[b]{2}{*}{ Diagnosis } & \multicolumn{3}{|c|}{ Patient } & \multicolumn{7}{|c|}{ Before relief of stenosis } & \multicolumn{7}{|c|}{ After relief of stenosis } \\
\hline & $\begin{array}{c}\dot{0} \\
\mathbf{Z} \\
\dot{0} \\
\tilde{U} \\
\tilde{U}\end{array}$ & 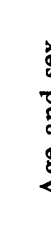 & & 苞 & 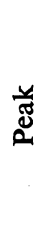 & 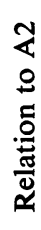 & 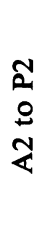 & 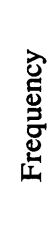 & 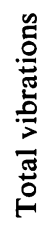 & 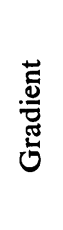 & مَّْ & 离 & 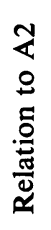 & 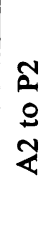 & 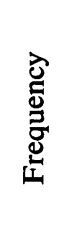 & 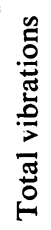 & 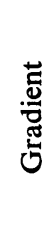 \\
\hline Aortic stenosis & $\begin{array}{l}1 \\
2 \\
3\end{array}$ & $\begin{array}{l}38 \\
45 \\
44\end{array}$ & $\begin{array}{l}\mathbf{F} \\
\mathbf{F} \\
\mathbf{F}\end{array}$ & $\begin{array}{l}22 \\
25 \\
19\end{array}$ & $\begin{array}{l}18 \\
17 \\
17\end{array}$ & $\begin{array}{l}\mathbf{B} \\
\mathbf{B} \\
\mathbf{B}\end{array}$ & 二 & $\begin{array}{l}220 \\
210 \\
200\end{array}$ & $\begin{array}{l}62 \\
53 \\
38\end{array}$ & $\begin{array}{r}85 \\
100 \\
45\end{array}$ & $\begin{array}{l}20 \\
17 \\
18\end{array}$ & $\begin{array}{l}15 \\
15 \\
14\end{array}$ & $\begin{array}{l}\mathbf{B} \\
\mathbf{B} \\
\mathbf{B}\end{array}$ & - & $\begin{array}{l}150 \\
190 \\
120\end{array}$ & $\begin{array}{l}30 \\
32 \\
22\end{array}$ & $\begin{array}{l}40 \\
35 \\
15\end{array}$ \\
\hline $\begin{array}{l}\text { Pulmonary stenosis with } \\
\text { normal aortic root }\end{array}$ & $\begin{array}{l}4 \\
5 \\
6 \\
7 \\
8 \\
9\end{array}$ & $\begin{array}{l}15 \\
16 \\
16 \\
13 \\
10 \\
36\end{array}$ & $\begin{array}{l}\mathbf{M} \\
\mathbf{F} \\
\mathbf{F} \\
\mathbf{F} \\
\mathbf{M} \\
\mathbf{F}\end{array}$ & $\begin{array}{l}28 \\
29 \\
33 \\
25 \\
34 \\
34\end{array}$ & $\begin{array}{l}17 \\
19 \\
32 \\
20 \\
25 \\
18\end{array}$ & $\begin{array}{l}\mathbf{A} \\
\mathbf{A} \\
\mathbf{A} \\
\mathbf{A} \\
\mathbf{A} \\
\mathbf{A}\end{array}$ & $\begin{array}{r}9 \\
15 \\
9 \\
8 \\
16 \\
10\end{array}$ & $\begin{array}{l}190 \\
220 \\
200 \\
210 \\
200 \\
200\end{array}$ & $\begin{array}{l}53 \\
64 \\
66 \\
53 \\
68 \\
68\end{array}$ & $\begin{array}{r}56 \\
100 \\
60 \\
18 \\
-\end{array}$ & $\begin{array}{l}20 \\
22 \\
21 \\
20 \\
27 \\
32\end{array}$ & $\begin{array}{l}14 \\
15 \\
15 \\
10 \\
20 \\
16\end{array}$ & $\begin{array}{l}\mathbf{A} \\
\mathbf{O} \\
\mathbf{A} \\
\mathbf{A} \\
\mathbf{A} \\
\mathbf{A}\end{array}$ & $\begin{array}{l}5 \\
8 \\
5 \\
4 \\
7 \\
9\end{array}$ & $\begin{array}{l}120 \\
170 \\
190 \\
160 \\
190 \\
170\end{array}$ & $\begin{array}{l}24 \\
37 \\
40 \\
32 \\
51 \\
54\end{array}$ & $\begin{array}{r}39 \\
20 \\
15 \\
4 \\
- \\
-\end{array}$ \\
\hline $\begin{array}{l}\text { Tetralogy of Fallot } \\
\text { (a) Valvular }\end{array}$ & $\begin{array}{l}10 \\
11 \\
12 \\
13 \\
14\end{array}$ & $\begin{array}{r}4 \\
12 \\
6 \\
5 \\
7\end{array}$ & $\begin{array}{l}\mathbf{M} \\
\mathbf{F} \\
\mathbf{M} \\
\mathbf{M} \\
\mathbf{M}\end{array}$ & $\begin{array}{l}20 \\
28 \\
24 \\
21 \\
21\end{array}$ & $\begin{array}{l}14 \\
25 \\
19 \\
15 \\
13\end{array}$ & $\begin{array}{l}\mathbf{O} \\
\mathbf{A} \\
\mathbf{O} \\
\mathbf{B} \\
\mathbf{B}\end{array}$ & $\begin{array}{l}\overline{12} \\
12 \\
-\end{array}$ & $\begin{array}{l}210 \\
230 \\
190 \\
240 \\
170\end{array}$ & $\begin{array}{l}42 \\
64 \\
46 \\
50 \\
36\end{array}$ & $\begin{array}{r}72 \\
132 \\
64 \\
57 \\
-\end{array}$ & $\begin{array}{l}18 \\
27 \\
20 \\
11 \\
18\end{array}$ & $\begin{array}{r}13 \\
20 \\
10 \\
8 \\
10\end{array}$ & $\begin{array}{l}\mathbf{B} \\
\mathbf{O} \\
\mathbf{B} \\
\mathbf{B} \\
\mathbf{B}\end{array}$ & $\begin{array}{r}-7 \\
7 \\
7\end{array}$ & $\begin{array}{l}140 \\
180 \\
160 \\
200 \\
170\end{array}$ & $\begin{array}{l}25 \\
50 \\
32 \\
22 \\
31\end{array}$ & $\begin{array}{r}71 \\
133 \\
38 \\
30 \\
-\end{array}$ \\
\hline (b) Infundibular & $\begin{array}{l}15 \\
16 \\
17 \\
18 \\
19\end{array}$ & $\begin{array}{r}14 \\
16 \\
9 \\
5 \\
9\end{array}$ & $\begin{array}{l}\mathbf{F} \\
\mathbf{M} \\
\mathbf{M} \\
\mathbf{F} \\
\mathbf{M}\end{array}$ & $\begin{array}{l}24 \\
25 \\
26 \\
20 \\
23\end{array}$ & $\begin{array}{l}25 \\
14 \\
16 \\
10 \\
15\end{array}$ & $\begin{array}{l}\mathbf{O} \\
\mathbf{O} \\
\mathbf{O} \\
\mathbf{B} \\
\mathbf{A}\end{array}$ & $\begin{array}{r}\overline{7} \\
\overline{7}\end{array}$ & $\begin{array}{l}210 \\
220 \\
230 \\
210 \\
280\end{array}$ & $\begin{array}{l}50 \\
55 \\
60 \\
42 \\
64\end{array}$ & $\begin{array}{l}57 \\
38 \\
51 \\
- \\
\end{array}$ & $\begin{array}{l}23 \\
31 \\
26 \\
21 \\
29\end{array}$ & $\begin{array}{r}12 \\
12 \\
15 \\
8 \\
15\end{array}$ & $\begin{array}{l}\mathbf{O} \\
\mathbf{O} \\
\mathbf{O} \\
\mathbf{B} \\
\mathbf{A}\end{array}$ & $\begin{array}{l}12 \\
10 \\
10 \\
10\end{array}$ & $\begin{array}{l}150 \\
160 \\
160 \\
180 \\
200\end{array}$ & $\begin{array}{l}35 \\
50 \\
42 \\
38 \\
58\end{array}$ & $\begin{array}{l}43 \\
35 \\
45 \\
- \\
-\end{array}$ \\
\hline $\begin{array}{l}\text { (c) Valvular and infundi- } \\
\text { bular }\end{array}$ & 20 & 5 & $\mathbf{M}$ & 25 & 18 & $\mathbf{O}$ & 9 & 210 & 53 & - & 23 & 12 & $\mathbf{O}$ & 11 & 160 & 37 & 一 \\
\hline
\end{tabular}

The duration of the murmur is measured in hundredths of a second. The peak is the interval in hundredths of a second between the onset of the maximal vibrations of the first heart sound and the point of maximal intensity of the murmur. Relation to A2 shows whether the murmur ends before (B), after (A), or at (O) the beginning of the aortic component of the second heart sound. A2 to P2 is the interval between the aortic and pulmonary components of the second heart sound. The frequency is in cycles a second. The total vibrations are the frequency times the duration. The gradient is measured in $\mathrm{mm}$. $\mathrm{Hg}$ by direct puncture at the time of operation.

Logarithmic (high frequency) phonocardiograms were taken before and after operation. The post-operative tracings were obtained at least two weeks after operation. The tracings were taken on a Sanborn Stethocardiette using a technique previously described (Wells et al., 1949). The patients were supine and stopped breathing at the end of a quiet expiration for long enough to record six heart beats. Straining was carefully avoided and no significant changes have been attributable to the arrested breathing. 
PREOPERATIVE. POSTOPERATIVE.

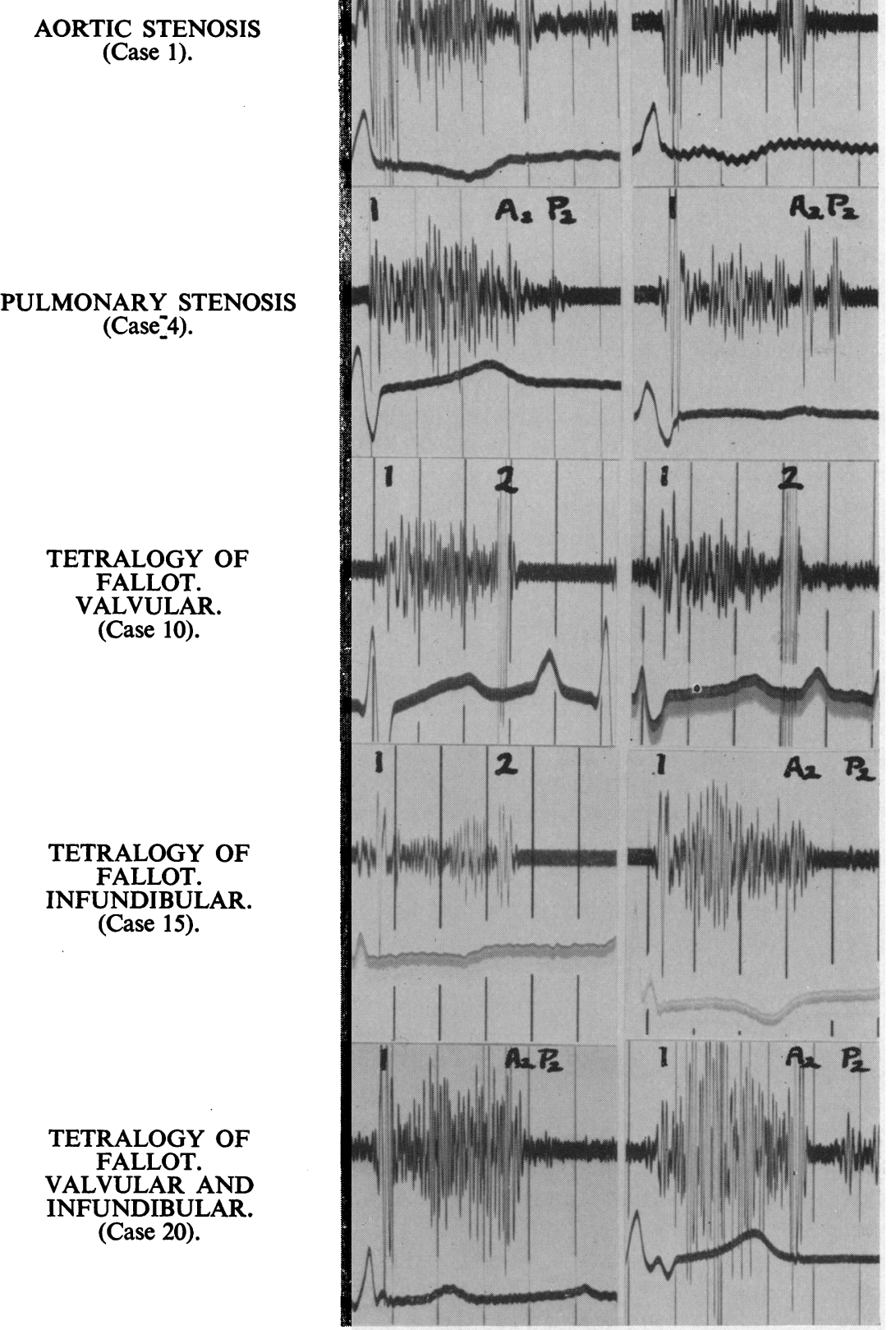

Fig. 1.-Phonocardiograms before and after operation. Upper tracings logarithmic (high frequency) phonocardiograms at the point of maximal intensity of the murmurs. Lower tracing: electrocardiogram lead II. Time lines $0 \cdot 1 \mathrm{sec}$. (1) First heart sound. (2) Second heart sound. (A2) Aortic component of second heart sound. (P2) Pulmonary component of second heart sound. 
In most cases the pressure gradient across the stenosis was measured at operation both before and after the valvotomy or infundibular resection. The gradients were measured by an electromanometer.

No attempt was made to assess the absolute intensity of the murmurs studied. This depends on the thickness of the tissues between the source of the murmur and the microphone, and is not proportional to the degree of stenosis. The following features were studied.

(1) The intervals between the beginning of the first heart sound and the beginning and end of the murmur.

(2) The duration of the murmur.

(3) The time of maximal intensity of the murmur (measured from the beginning of the first heart sound).

(4) The relationship of the end of the murmur to the pulmonary and aortic components of the second heart sound.

(5) The time interval between these components.

(6) The frequency of the vibrations constituting the murmur.

The beginning of the maximal vibrations of the first sound was considered to be the most reasonable time from which to measure the beginning and end of the systolic murmur and its point of maximal intensity. The interval between the pulmonary and aortic components of the second heart sound was similarly measured from the onset of the maximal vibrations of each. The frequency of the vibrations constituting the systolic murmur was measured by counting with a hand lens the number of vibrations in a tenth of a second. Slightly notched or slurred vibrations were counted as one. Only when the notching amounted to a change of direction were two vibrations counted. Such a system of counting vibrations naturally depends on the degree of amplification used in recording the sound tracings. This was kept reasonably constant by employing the same volume control setting for all the tracings.

\section{RESULTS}

The most consistent change in the tracings following operation was that the frequency of the vibrations constituting the systolic murmur was lower (Table I). A reduction of frequency was present in nineteen cases, while in one case the frequency was unchanged. Indeed the pre-operative patients could be roughly distinguished from the post-operative ones on the basis of frequency. A frequency of 200 cycles per second or greater was present in seventeen patients before operation. A frequency of less than 200 cycles per second was present in eighteen patients after operation. There was no close correlation between the frequency and the pressure gradient across the stenosis. This may be partly because the phonocardiograms were taken at rest in bed whereas the gradients were measured under anæsthesia with the chest and pericardium opened.

The length of the systolic murmur was less closely related to the severity of the stenosis. The pre-operative length was greater in pure pulmonary stenosis than in the other conditions. The post-operative length was reduced by about a fifth in all cases in which the stenosis was valvular. In infundibular stenosis, however, the murmur was longer in three, the same in one, and slightly shorter in one.

The frequency in cycles per second multiplied by the length of the murmur gives the approximate total vibrations. The figures can be seen in the Table. The total vibrations gave a poorer indication of the severity of the stenosis than the frequency.

The time of onset of the murmur did not vary much. After operation ten started earlier, six were unchanged, and four started later. The time of ending of the murmur was much more interesting. Before operation the murmur ended late in all cases of pulmonary stenosis with normal aortic root. In these cases the murmur extended past the aortic component of the second heart sound. After operation the end of the murmur was earlier in all cases of valvular stenosis, but later in all cases of infundibular stenosis. The earlier ending of the murmur after valvotomy was sometimes such that the murmur stopped before the aortic component of the second heart sound. 
The later ending after infundibular resection never extended past the aortic component of the second heart sound except in one case of acyanotic tetralogy of Fallot. In this case the murmur extended beyond the aortic component both before and after infundibular resection.

The time of maximal intensity of the murmur is conveniently termed the peak. This was late in pre-operative tracings and became earlier after operation in all cases except one. This was a case of tetralogy of Fallot with infundibular stenosis, and no change was found in the peak of the murmur. The peak followed the first heart sound by 0.15 seconds or more in thirteen out of twenty cases before operation. After operation it was less than $0 \cdot 15$ seconds after the first heart sound in seventeen cases.

The interval between the pulmonary and aortic components of the second heart sound could be measured in only 11 patients before operation. Six of these were patients with pulmonary stenosis and normal aortic root. In these the interval before operation appeared proportional to the pressure gradient found at operation. After operation the interval was reduced, and coincided roughly with the post-operative pressure gradient. There was a measurable interval between the aortic and pulmonary components of the second sound in only five of the eleven cases of tetralogy of Fallot before operation. In two patients with valvular stenosis the interval decreased after operation, while in two with infundibular stenosis and one with valvular and infundibular stenosis the interval increased. In a further three patients with tetralogy of Fallot a pulmonary component of the second heart sound was recorded only after operation-giving a measurable postoperative interval in eight of the eleven patients.

\section{Discussion}

The tracings were analysed to decide whether the character of the systolic murmur gave an indication of the degree of stenosis present. The various points of interest that have come to light during the study will be discussed later.

Can the severity of stenosis be assessed from the systolic murmur? This question will only be fully answered when established cases of idiopathic dilatation of the pulmonary artery and cases of mild pulmonary stenosis are analysed. The present series is only the first step towards the answer. It shows that there are changes in the systolic murmur after the relief of stenosis. The changes are such that the tracings before and after operation can usually be identified. The features involved are the frequency of the vibrations constituting the murmur and the time of maximal intensity of the murmur. When there is a normal aortic root there is the added factor that the gradient across the stenosed pulmonary valve can be assessed by the interval between the aortic and pulmonary components of the second heart sound.

The relationship of the frequency of the vibrations constituting a systolic murmur to the cause of the murmur has been discussed in a previous paper (Wells, 1957). The murmur of mitral regurgitation has often a frequency of over 200 cycles a second which represents a gradient of almost the whole ventricular pressure. The slight or moderate ejection murmurs which sometimes occur in a heart that is otherwise normal are considered innocent. These have a frequency of about 170 cycles a second. The coarse innocent murmurs are different from ejection murmurs in that they are briefer, occur earlier in systole, and have a frequency of about 110 cycles a second.

The earlier peak of intensity following valvotomy has not previously been described. Mannheimer and Jonsson (1954) have shown that in cases of pulmonary stenosis the murmur is earlier when the right ventricular pressure is below $70 \mathrm{~mm}$. $\mathrm{Hg}$. It is not unreasonable to relate the peak of intensity of the systolic murmur in aortic stenosis to the delay in the peak of aortic pressure. No doubt the same factors apply in pulmonary stenosis. It has been found that there is a relationship between the severity of aortic stenosis and the delay in the peak of aortic pressure (Dow, 1940; Goldberg et al., 1954). The period of ejection is also longer in aortic stenosis (Bailey et al., 1956). It is therefore possible that the length of a systolic murmur and the peak of its intensity will throw light on the period of ejection and the form of the arterial pulse. 
Other Points of Interest Arising from the Present Study. Two of the eleven patients with tetralogy of Fallot were acyanotic at rest. In these the systolic murmur extended beyond the aortic component of the second heart sound. In none of the cyanotic cases did this occur. The diagnosis of tetralogy of Fallot was confirmed by the equal pressures in the ventricles and the free passage of a sound from the right ventricle to the aorta. The stenosis must clearly have been sufficiently mild for the pulmonary flow to be nearly as large as the aortic flow. Although one patient had valvular and the other infundibular stenosis, the auscultatory findings did not differ from pulmonary stenosis with a normal aortic root.

In the patients with tetralogy of Fallot the phonocardiograms did not show the differences described by Mannheimer and Jonsson (1954) that enable valvular stenosis to be differentiated from infundibular stenosis. The behaviour of those after infundibular resection did, however, differ from those after valvotomy. This supports their explanation of the early termination of the murmur in infundibular stenosis due to contraction in late systole of the infundibular region.

The pulmonary component of the second heart sound was recorded before operation in five of the eleven patients with tetralogy of Fallot and after operation in eight. This does not agree with the findings of Kjellberg et al. (1955), and Leatham and Weitzman (1956) who believe that the presence of a pulmonary component of the second heart sound is against the diagnosis of tetralogy of Fallot. From the present series it can be said that failure to record a pulmonary component of the second heart sound is more in favour of a diagnosis of Fallot's tetralogy than of pulmonary stenosis with a normal aortic root.

\section{SUMMARY}

The systolic murmur was studied by phonocardiography in twenty patients before and after aortic or pulmonary valvotomy or infundibular resection.

The loudness of the murmur was not considered important and the significant changes were of the frequency of the vibrations and the timing of peak intensity. A frequency above 200 cycles per second and a peak later than $0 \cdot 15$ seconds after the first sound indicate severe stenosis.

In tetralogy of Fallot it was not possible to determine from pre-operative tracings whether the stenosis was valvular or infundibular. It was, however, found that valvotomy shortened the murmur while infundibular resection lengthened it.

A pulmonary component of the second sound was recorded in eight of eleven cases of tetralogy of Fallot. This component does not therefore establish the integrity of the aortic root.

Two patients with acyanotic tetralogy of Fallot had systolic murmurs that obscured the aortic component of the second heart sound. In none of the cyanotic cases did this occur.

I wish to thank Mr. O. S. Tubbs and Mr. I. M. Hill for permission to study their cases and for their continued encouragement and interest.

\section{REFERENCES}

Bailey, C. P., Bolton, H. E., Nichols, H. T., Jannson, W. L., and Litwak, R. S. (1956). J. Thor. Surg., 31, 375.

Currens, J. H., Kinney, T. D., and White, P. D. (1945). Amer. Heart J., 30, 491.

Donzelot, E., and D'Allaines, F. (1954). Traité des Cardiopathies Congenitales. 1st ed., Paris, p. 235.

Dow, P. (1940). Amer. J. Physiol., 131, 432.

Dow, J. W., Levine, H. D., Elkin, M., Haynes, F. W., Hellems, H. K., Whittenberger, J. W., Ferris, B. G., and Goodale, W. T. (1950). Circulation, 1, 267.

Downing, D. F. (1956). Circulation, 14, 188.

Goldberg, H., Bakst, A. A., and Bailey, C. P. (1954). Amer. Heart J., 47, 527.

Greene, D. G., Baldwin, E. de F., Baldwin, J. S., Himmelstein, A., Roh, C. E., and Cournand, A. (1949). Amer. J. Med., 6, 24.

Kjellberg, S. R., Mannheimer, E., Rudhe, U., and Jonsson, B. (1955). Diagnosis of Congenital Heart Disease. 1st ed. Chicago, p. 143 .

Leatham, A., and Weitzman, D. (1956). Second European Congress of Cardiology. Stockholm.

Mannheimer, E., and Jonsson, B. (1954). Acta pediat. Supp. 100, p. 167.

Ordway, N. K., Levy, L., Hyman, A. L., and Bagnetto, R. L. (1950). Amer. Heart J., 40, 471.

Reinhold, J. D. N., and Nadas, A. S. (1954). Amer. Heart J., 47, 405.

Vogelpoel, L., and Schrire, V. (1955). Circulation, 11, 714.

Wells, B. G., Rappaport, M. B., and Sprague, H. B. (1949). Amer. Heart J., 37, 586.

(1957). Brit. Heart J., 19, 129. 